\title{
Televisión y familia en la formación del sujeto
}

\author{
Enrique Guinsberg ${ }^{1}$
}

Desde la primera infancia y a lo largo de nuestra vida cotidiana estamos expuestos a los atractivos mensajes de un aparato receptor que ya forma parte de la ecología familiar.

Pablo Arredondo (1989: 7)

1

NTER Y TRANSDISCIPLINARIEDAD no son una excepción a la lamentable contradicción que se presenta entre lo que siempre se dice que debe hacerse pero no se hace. Carencia que hoy, como nunca hasta ahora, produce serias dificultades y trabas a la investigación de los problemas que se presentan dentro del amplio campo de las ciencias sociales en general.

En tal contexto se presenta una situación no curiosa pero sí clara de lo apuntado: no hay psicoanalista o psicólogo que deje de comprender la incidencia de los medios masivos de difusión en los sujetos de nuestro tiempo, ni comunicólogo que niegue la importancia del conocimiento del psiquismo en múltiples problemas de su campo. Pero tal reconocimiento muy pocas veces pasa de la teoría y busca los vínculos y articulaciones entre ambas disciplinas, justificándolo con la aceptación de la ignorancia de esferas que consideran no son de su específica competencia. Aceptando sin conceder que ello sea cierto, son muy escasas las búsquedas de tal vinculación y/o encuentro a través de marcos de estudio al menos interdisciplinario.

El problema aquí planteado se inscribe en esa carencia y limitación, por ello es necesario señalar tal necesidad, ya encarada en trabajos anteriores (Guinsberg, 1985, 1991a y b, 1996) que en líneas generales plantean lo imperioso de la construcción de una dialéctica entre los procesos de emisión y de recepción de los contenidos de los medios masivos de difusión, facetas imposibles de abarcar sin una integración (subrayado para indicar que no se trata de una suma) de conocimientos sobre aspectos político-sociales y subjetivos).

La importancia del problema surge de la trascendencia y magnitud, actuales y existentes desde hace bastante tiempo, de los medios masivos de difusión, que

1. Universidad Autónoma Metropolitana-Xochimilco (UAM-X). 
para muchos estudiosos son hoy las instituciones hegemónicas del mundo presente. En consecuencia resulta imperioso estudiar el aporte de dichos medios al proceso de constitución del modelo de sujeto psíquico que cada marco social requiere para mantenerse y reproducirse, como también los aspectos subjetivos que posibilitan y permiten tanto el impacto como la aceptación o el rechazo de los programas y contenidos predominantes en los medios.

Es incuestionable que hoy los medios masivos de difusión (sobre todo la TV) son para los niños, prácticamente desde el mismo nacimiento, parte fundamental y estructural de su vida: están con ellos más tiempo que en una escuela, que les resulta menos placentera y donde, seguramente, aprenden menos respecto de la vida, costumbres y normas sociales. Todo esto pueden verlo y lo saben de hecho no sólo los educadores, que observan la disminución de su peso educativo -quizás no tanto, aunque sustancial, en el suministro de conocimientos, sino sobre todo en las esferas mucho más importante de normas, ideales, ideologías, etc.-, sino también los estudiosos e investigadores de las ciencias sociales en general que ven cómo los niños juegan a lo que les muestran los programas de moda, quieren ser como sus personajes; así también aspectos similares en adolescentes y adultos.

En este sentido vale recordar la lucidez de uno de los escasos sociólogos norteamericanos críticos, no funcionalistas, cuando resume el problema señalando:

Los medios masivos de comunicación : 1) le dicen al hombre de masa quién es: le prestan una identidad; 2) le dicen qué quiere ser: le dan aspiraciones; 3 ) le dicen cómo lograrlo: le dan una técnica; 4) le dicen cómo puede sentir que es así, incluso cuando no lo es: le dan un escape (Wright Mills, 1957).

Es por ello que no constituye ninguna exageración afirmar que los medios son actualmente una verdadera "escuela" para la estructuración de los sujetos, como consecuencia lógica de que "la televisión ha tenido una mayor influencia en la estructura de la vida diaria que todas las demás novedades aparecidas en el presente siglo" (Erausquin y otros, 1984: 20). Desde una perspectiva teórica psicoanalítica - y como parte de la relación hombre-cultura estudiada en un artículo anterior (Guinsberg, 1991c) - , no puede dejar de investigarse y comprenderse el aporte de los medios a la conformación del aparato psíquico: son quienes más ofrecen una determinada visión de lo que se convertirá en principio de realidad (que, como es conocido, tiende a ir reemplazando al principio del placer de los inicios de la vida del niño, lo que le permite el principio de socialización), y ofrecen constantes y múltiples modelos identificatorios -ambos aspectos centrales de la constitución del Yo-, a más de mostrar de manera permanente lo que es lo "bueno" y lo "malo" (con sus consecuentes premios y castigos), que se convierten en ejemplos para el Superyó. A esto deben agregarse técnicas para lograr lo que se indica, propuestas de cumplimiento de deseos, ofrecimiento de fantasías, etcétera. 
Claro que estos resultados no podrían darse si los medios no actuasen sobre aspectos específicos del psiquismo de los sujetos. Los contenidos de los medios logran éxito porque ofrecen respuestas a las necesidades subjetivas de los receptores, fundamentalmente a aquellas de tipo emocional y afectivo. $Y$ éste es un aspecto sobre el que el psicoanálisis puede ofrecer mucho para la comprensión de los procesos comunicativos en general, y del llamado "momento de la recepción" en particular.

\section{Familia y medios}

Pero ipuede y debe incluirse a los medios cuando la mayor parte de los estudios psicológicos y psicoanalíticos clásicos han visto y ven a la familia como la institución básica y casi única en el proceso de formación del sujeto? El problema, en relación con los medios, puede verse al menos desde cuatro perspectivas.

La primera tiene que ver con la clásica discusión sobre la hegemonía de las distintas instituciones en el proceso de socialización. Si bien hoy la familia sigue teniendo un rol fundamental e irrenunciable, también es cierto que su peso es ya bastante menor al de épocas pasadas; y que otras instituciones, los medios sobre todo, ocupan un lugar que no puede negarse. No es éste el espacio para demostrar este papel hegemónico, aspecto desarrollado en los artículos mencionados y en una amplia bibliografía; baste ahora sólo recordar que la presencia de los medios en la actualidad es permanente en todos los ámbitos sociales y que tiende a acrecentarse de una manera imposible de prever ante el actual desarrollo electrónico e informático, con una incidencia socializadora/ideologizadora aún mayor cuando existen dificultades para lograr una educación formal.

En esta perspectiva $H$. Marcuse ya lo plantaba en la década de los 'años cicuenta:

El desarrollo social, que ha destronado al individuo como sujeto económico, también ha reducido al mínimo la función individualizadora de la familia en favor de potencias mucho más efectivas. La nueva generación es llevada al principio de la realidad menos por medio de la familia que por medios exteriores a ésta; la juventud aprende a conocer las formas de comportamiento y las reacciones socialmente útiles fuera de la protegida esfera privada de la familia. El padre moderno no es ningún representante efectivo del principio de realidad y la relajación de la moral sexual facilita el dejar atrás el complejo de Edipo: la lucha contra el padre ha perdido mucho de su decisiva importancia psicológica (Marcuse, 1971: 538).

Y años más tarde continúa su idea:

Desde el nivel preescolar, las pandillas, la radio y la televisión establecen el modelo de conformismo y la rebelión; las desviaciones del modelo son castigadas no tanto dentro de la familia como fuera de ella y en su contra. Los expertos en los medios de difusión transmiten los valores requeridos; ofrecen perfecto entrenamiento en efi- 
ciencia, tenacidad, personalidad, sueños, romances. Contra esta educación la familia ya no puede competir (Marcuse, 1986: 109).

Más allá de la discusión sobre sus afirmaciones respecto del complejo de Edipo, la misma idea es planteada desde diferentes ámbitos teóricos psicológicos, sociales y comunicológicos. Entre los primeros, M. Schneider considera:

[...] los conocimientos y habilidades necesarios para el mundo moderno, en perpetuo cambio, no pueden desarrollarse ya de generación en generación dentro de la familia. Como la familia burguesa no puede transmitir ya el saber necesario para el proceso de producción, también va perdiendo más y más su clásico cometido educador (Schneider, 1979: 372). ${ }^{2}$

Por su parte, un investigador de la comunicación lo atestigua en un trabajo de campo con los purépechas en Michoacán, donde observa que "la familia como núcleo social en el cual se generan y reproducen los componentes esenciales de la cultura de esta etnia" se han visto modificados al llegar la TV, que "ha venido a atacar precisamente a este núcleo y su capacidad generadora y reproductora de cultura".3

En un ámbito distinto, otros investigadores perciben los cambio que la TV produce tanto en la reproducción cultural como en la dinámica familiar. Una investigadora argentina no vacila en señalar que "a medida que el nin̄o progresa, la escuela, los compañeros, la televisión y los deportes compiten con los padres como agentes de socialización", aunque previamente había encabezado partes de su libro con citas categóricas de conocidos autores: de Marshall McLuhan, "el consorcio mundial de información, engendrado por los medios electrónicos, excede mucho la influencia que hasta ahora podían ejercer papá y mamá", y de Ulla Johnson-Samaragdi:

[...] con la cantidad de horas de TV que vemos, desde niños nadamos como peces en un mar de imágenes de colores; es el principal relator de historias de nuestra cultura actual, y en ocasiones suplanta la influencia de padres, maestros y líderes religiosos (Peyrú, 1993: 105-117, 213).

Otros estudiosos destacan que los padres que se han apartado temporalmente de la televisión juegan más con sus hijos; también indican que una encuesta

2. Aunque, por supuesto, tal limitación es general y no privativa de la familia burguesa.

3. Es cierto que se trata de una investigación pequeña y focalizada en un estrecho ámbito local, pero ello no cambia que sus conclusiones sean expresión de un fenómeno mayor al compararse la vida en la comunidad antes y después de la llegada de la televisión. Entre esas condiciones el mostrar que la TV "se ha introducido en la intimidad del hogar mismo, modificando las relaciones de convivencia hacia el interior de él": por ejemplo la disposición del mobiliario, donde el centro de la comunicación familiar era el fogón de la cocina y fue reemplazado por el aparato de TV en la sala, con todo lo que esto significa para tal comunicación (Gil Olivo, 1987: 29). 
presentada en un congreso europeo de psiquiatría en 1979 mostró que "la TV disminuye y anula la comunicación familiar (de los niños estudiados, $40 \%$ preferían la televisión a sus padres y $20 \%$ la preferían a sus madres)", e informan que Klaus Amman, ponente en el IV Congreso Internacional "Familia y Medios de Comunicación", realizado ese mismo año en Zurich, calificó a la TV como "abuela electrónica" y "jefe fantasma de familia" por convertirse en dictadora de los horarios familiares "hasta el punto de que las visiones proféticas del Farenheit 451 de Ray Bradbury $u$ otras novelas de anticipación, cada vez parecen menos exageradas, más realistas" (Erausquin y otros, 1984: 23-44-176). ${ }^{4}$

Desde un punto de vista psicoanalítico -en este caso proveniente de su campo institucional y ortodoxo-, se reitera lo conocido de la utilización de la TV como "niñera mecánica" 5 y las consecuencias de esto y de su uso constante: pérdida de atención de los miembros familiares a otros y los cambios que esto provoca en la comunicación; necesidad de investigar los efectos de la TV en la personalidad, etc., (Soifer, 1981: 14-43).

De manera menos académica pero muy gráfica plantea algo similar un connotado psicólogo social: "no hay más triángulo en la familia, ya es un cuadrilátero, porque el televisor es un tío psicópata que se incluyó y los sedujo a todos" (Moffat, 1988: 88). Expresiones que no son más que reafirmaciones de la frase que abre el presente trabajo, las que reitera una estudiosa ya citađa: "la relación de los niños actuales con la pequeña pantalla es una relación íntima” porque "desde la primera mamada los niños actuales están 'envueltos' por el medio televisivo", ya que "el televisor es un miembro más de la familia" (Peyrú, 1993: 13-17-20).

Y aunque nunca dejó de pensarse que la familia ha sido, sigue siendo y nada indica que dejará de ser, una institución central y primaria del proceso de conversión en sujeto, hoy existe una dinámica de cambio que no puede desconocerse en relación con otras instituciones, y que de algún modo modifica el papel familiar. Ya se verá que esto influye en las demás perspectivas.

Expresión de todo lo señalado es que los medios se han convertido, o tienden a hacerlo, en los articuladores con otras instituciones centrales del mundo actual, entre ellas las iglesias y la escuela formal (transmitiendo o siendo expresiones de diferentes cultos, actuando como "tele-escuela", etc.). Y si bien sería exagerado afirmar que también lo hacen o lo intentan y logran con la familia, no lo es destacar cómo buscan (y consiguen) incorporarse a ella como un nuevo miembro, participante e interviniente. De esta manera y tal como ya se mencionó, el poder y la influencia familiar se relativizan, lo que han comprendido muy bien los sistemas de poder, que buscan establecer una especie de alianza medios-familia para consolidar sus objetivos sociales, políticos, etc. Por separado, ninguna

4. Respecto a la relación padres-hijos-televisor, véase en Bradbury el magnífico, revelador y terrorífico cuento "La pradera", en el libro El hombre ilustrado, Minotauro, Buenos Aires.

5. Otros autores utilizan términos diferentes pero con parecida significación: "abuela electrónica" y "jefe fantasma de la familia" (Erausquin y otros, 1984: 176), "baby sitter electrónico", "tercer padre" y "abuelo televisor" (Peyrú, 1993: 18). 
de ambas instituciones garantiza el grado de eficiencia en el proceso socializador de un mundo cada vez más complejo y diversificado.

Pero si la familia no puede satisfacer las altas necesidad de capacitación (y a veces de socialización-ideologización), sí ofrece el marco propicio -es decir, la base afectiva imprescindible - para la constitución de los sujetos, o sea el cimiento para la internalización de los contenidos de los medios. Esta complejidad de la familia actual es porque su relación

[...] con la infraestructura cultural de la sociedad debilita su autonomía ideológica pero al mismo tiempo la enriquece discursivamente, [ya que] la familia no es la célula original de la sociedad, sino el vértice nodal donde se entretejen, mediatizan y potencias todas las contradicciones y determinaciones sociales (González, 1993: 22).

Comprendiendo esta realidad es que ya los asesores del expresidente Nixon proponían, con base en la experiencia de la exitosa serie Plaza Sésamo, la realización de un programa de vinculación medios-familia-escuela, plan que pretendía derrumbar el muro entre escuela y hogar ya que "las nuevas tecnologías de comunicación permitirán poner fin a la segregación entre la institución escolar y la institución familiar", por estimarse "que en el año 2000 la educación será dispensada en gran parte en el hogar, de manera permanente por vía electrónica". Las distintas fases del proyecto planteaban que "cada hogar se convertiría en escuela, gracias a un soporte electrónico conectado a un sistema central de computación situado en un centro de enseñanza". De tal manera "el fin de la segregación entre escuela y hogar sería la ocasión de insistir sobre la importancia del papel de los padre, llamados a convertirse en 'monitores electrónicos' de sus hijos".

En una intención que podría haber parecido de ciencia-ficción, ya anticipada por R. Bradbury y muchos futurólogos, pero que hoy se observa nada fantasiosa,

el nuevo sistema de electronización de la enseñanza tendría a su cargo la formación del niño desde la más tierna edad, no quedando en la vida del niño y la madre ni un solo resquicio que escape a la influencia de los medios audiovisuales (Mattelart, 1977: 216).

Proyecto aún no completamente realizado por la educación "formal" pero sí para una educación amplia en el sentido general del término, tanto por la presencia de la TV sobre el niño casi desde su nacimiento, por las horas que se encuentra frente a ella, como porque a su vez las familias actuales ya están educadas por la misma y transmiten a sus hijos una "cultura televisiva".

Cultura televisiva que destacan y reiteran quienes investigan el problema así como las múltiples investigaciones que, en el mundo entero muestran el importante tiempo que los niños pasan frente al televisor. Una de ellas indica que "antes de los tres años de edad, el 95 por ciento de los niños en la Ciudad de México ya han adquirido el hábito de 'ver la tele'", piden programas específicos y, "entre otras muchas cosas, aprenden los códigos y el lenguaje televisivo, a 
veces hasta con mucha más facilidad y rapidez que los mayores" (Orozco, 1992: 45). ${ }^{6}$

Esta relativa pero real disminución del peso familiar y el acrecentamiento del de los medios seguramente agradará a quienes han señalado la "crisis" de la familia, o a quienes cuestionan su papel actual achacándoles la responsabilidad en la producción de una también criticada "normalidad" mental (caso de David Cooper y Ronald Laing, entre otros), ${ }^{7}$ o de la esquizofrenia (Escuela de Palo Alto). Sin embargo, no parece haber razones para ser optimista en este sentido: por un lado los medios casi siempre hacen un frente común con la familia, con indudables contradicciones pero dentro de un marco ideológico "modernizado" aunque no antagónico respecto de los valores tradicionales; por otro lado, muchas de las características criticadas de la dinámica familiar también existen en los mensajes de los medios: por ejemplo, y como ya fuera planteado en los citados escritos anteriores y se verá más adelante, puede pensarse que la situación de doble vínculo no es privativa de la institución familiar sino también puede estar presente en otras instituciones, entre ellas el discurso de los medios.

Una segunda perspectiva, vinculada a la anterior y a las siguientes, afecta a la propia dinámica interna de la familia, y tal vez pueda condensarse gráficamente en la afirmación de quien dijera que el clásico "círculo" familiar se ha convertido en un "semicírculo" por la presencia del televisor, cambio espacial que provoca otros más importantes y cualitativos.

Recuérdese lo conocido respecto del tiempo que los niños están frente a lo que muchos intelectuales llaman "caja idiota", pero que para ellos (y también para los adultos) es la principal fuente de diversión, información, conocimiento, etc. Tiempo que surge por ausencia de alternativas, por escasez de espacios libres para juegos y los reales o supuestos peligros de estos en las urbes modernas, pero también porque múltiples veces los niños son empujados hacia un aparato convertido en "nin̄era electrónica" por necesidad de trabajo y ocupación de los adultos, creencia de éstos en su capacidad educativa, etcétera.

Esta especie de "teleadicción" se refuerza porque, también en múltiples oportunidades, la cada vez mayor complejidad y el agobio de la vida moderna hacen que los adultos busquen alivio y descanso en las programaciones televisi-

6. El autor escribe luego algo importante que se vincula con el peso actual de la educación formal y su vinculación con la hegemonía de la televisión: "Cuando entran a la escuela, cuando el niño deja de ser un 'preescolar', no llega al salón de clases con la 'mente virgen' -pedagógicamente hablando_ para el aprendizaje sino que se enfrentan al maestro y al libro de texto con una serie de experiencias y vivencias que si bien le apoyan y facilitan algunos nuevos aprendizajes, también, desgraciadamente le estorban e impiden otros haciendo así aún más ardua la tarea de sus educadores."

7. Recuérdese que en la década de los sesenta e inicios de los setenta tuvo fuerte auge una corriente crítica y alternativa dentro del campo psiquiátrico y de la "salud mental", (equívocamente conocida como antipsiquiatrías). Dentro de su vertiente inglesa se hizo un fuerte cuestionamiento al papel de la familia - tanto respecto de la producción de la "normalidad" como de psicopatología-, expresión del cual fueron textos como los de D. Cooper (1971) y el de R. Laing (1976). 
vas en su hogar. Todo este panorama amplía notablemente el peso y la presencia de ese medio de difusión, pero también reduce de manera cuantitativa y cualitativa los vínculos familiares, incluyendo los juegos de los padres con sus hijos. Este sería sin dudas un importante tema por estudiar y desarrollar teóricamente, con base en investigaciones de campo, lo que muy poco se ha realizado hasta ahora.

Algunas de las investigaciones llevadas a cabo señalan:

Las familias que se han apartado temporalmente de la televisión destacan el hecho de que, después de hacerlo, juegan muchas horas con sus chicos. Quienes nunca han sido teleadictos no incluyen entre sus actividades, de forma destacada, la de jugar con los niños. Resulta lícito deducir de aquí que el niño no televisualizado, necesita de un figura exterior a él —en este caso el padre o la madre- que cubra, con la incitación al juego y la actividad compartida, el vacío temporal que el televisor le ha dejado (Erausquin y otros, 1984: 23).

Acerca de esto recuérdese lo antes señalado por otro investigador en el Congreso Europeo de Psiquiatría respecto de la preferencia de la TV antes que a los padres. Otra realizada hace mucho tiempo, en 1955 y 1956, en Inglaterra (por lo que sus datos deben ser reexaminados hoy), mostraba que "los niños más rechazados por sus padres recurrían con mayor frecuencia a la TV" (Corona, 1989: 29).

Las otras dos perspectivas se encuentran íntimamente vinculadas a las anteriores y pueden ser consideradas derivaciones de ellas. Tienen que ver con el clásico papel familiar en el proceso de reproducción social y cultural de las actuales sociedades, junto con la estructuración de los sujetos, aspectos que desde el marco teórico psicoanalítico se relacionan con modelos identificatorios y construcción del principio de realidad, ambas facetas constitutivas del Yo.

\section{Medios, familia y procesos de identificación}

Como identificación se conoce al

[...] proceso psicológico mediante el cual un sujeto asimila un aspecto, una propiedad, un atributo de otro y se transforma, total o parcialmente, sobre el modelo de este; la personalidad se constituye y se diferencia mediante una serie de identificaciones (Laplanche y Pontalis, 1971: 191).

S. Freud siempre destacó la gran importancia de este proceso, razón por la cual en el diccionario de J. Laplanche y J. B. Pontalis se destaca que el mismo "ha adquirido progresivamente en la obra de Freud el valor central que más que un mecanismo psicológico entre otros, hace de él la operación en virtud de la cual se constituye el sujeto humano". Por eso S. Freud escribe: "los efectos de las primeras identificaciones, las producidas a la edad más temprana, serán 
universales y duraderos" (Freud, 1976a: 33), y consideró, como lo ha seguido haciendo el marco psicoanalítico en general, que los medios fundamentales son los miembros de la familia y personajes cercanos y de impacto.

No incluye a los medios, como no lo hace en toda su obra dada la escasa importancia que tenían en su época, pero sí lo hacen investigadores posteriores (aunque los analistas reconocen su incidencia pero no la estudian). G. Maletzke analiza el problema y considera inexplorada la cuestión de cuáles serían las semejanzas y diferencias entre las identificaciones "normales" (es decir con padres, por ejemplo) y las que se originan en los sistemas de difusión. De acuerdo con lo que entiende como planteos de la psicología profunda, considera que son dos las funciones que deben adscribirse a la identificación: la de aprendizaje y la de satisfacción sustitutiva; pero al margen de lo relativo y discutible de su interpretación del psicoanálisis al respecto, es importante reseñar la importancia que en ambas asigna a los medios, ya que, según su opinión, "en ambas orientaciones evidentemente la comunicación social es capaz de lograr más que la comunicación personal directa”. Considera que el círculo de personas que rodean a un niño no siempre es estrecho, por lo que numerosos deseos y necesidades quedan sin cumplirse.

No todo individuo encuentra en su ambiente social personalidades ricas y potentes, partícipes en el amor o en la sociabilidad, artistas y criminales, santos y neuróticos. La comunicación social ofrece una plenitud de tales figuras; por medio de la comunicación social, se amplía considerablemente el círculo de objetos potenciales de identificación; más allá de eso, el hombre, como ente dotado de fantasía, independientemente del espacio y del tiempo, aspira al encuentro con figuras de identificación que en realidad no existen; busca seres de leyenda y fábula, ángeles y diablos, al héroe, al superhombre, a la imagen ideal. Pero parece evidente, en cambio, que la potencia de fantasía del hombre promedio no es suficiente para satisfacer esta necesidad. En todo tiempo ha habido unos pocos que han creado figuras de esta índole para la multitud. Hoy la comunicación social, con sus posibilidades de configuración artística y de difusión técnica, se ha hecho cargo de esta tarea (Maletzke, 1976: 169).

Por supuesto no se trata de provocar una admiración ni racional ni basada en la calidad del actor o sus planteos, sino de lograr una integración psíquica de adoración y de admiración con una carga emocional y afectiva que ligue al público con su protagonista, transmisor de un papel y de una situación, lo que implica la introyección de los contenidos y características del personaje. Es fácil observar como una figura exitosa o de moda es imitada por sus seguidores, internalizando así de manera inconsciente tanto su imagen como sus valores. De tal manera que cuando un niño o un adolescente se viste o juega como su héroe de historieta o TV, está introyectando un modelo - con todas sus significaciones-, intentando ser o llegar a ser como él. En este sentido es importante señalar la dificultad de escapar a estas influencias producidas por los medios: no conocer a los héroes de moda o no jugar a ser ellos con otro niños implica marginación, con todo lo que esto significa para las personas. 
Si bien el proceso identificatorio sigue teniendo una base fundamental en la familia y en las figuras que rodean de manera cercana a los niños (maestros, familiares, personas cercanas), lo brevemente expuesto muestra que la intervención de los medios para nada es desdeñable y, por el contrario, merece la mayor de las atenciones. Ya se indicó que S. Freud no los incluye, pero tal carencia no puede continuar hoy. De cualquier manera, el mismo Freud escribe algo pertinente para nuestro tema:

[...] ya columbramos que la ligazón recíproca entre los individuos de la masa tiene la naturaleza de una identificación de clase (mediante una importante comunidad afectiva), y podemos conjeturar que esa comunidad reside en el modo de la ligazón con el conductor. Otro vislumbre nos dirá que estamos muy lejos de haber agotado el problema de la identificación; en efecto, nos enfrentamos con el proceso que la psicología llama "empatía" y que desempeña la parte principal de nuestra comprensión del Yo ajeno, el de las otras personas.

Y más adelante concluye sus observaciones:

[...] una masa primaria de esta índole es una multitud de individuos que han puesto un objeto, uno y el mismo, en el lugar de su ideal del yo a consecuencia de lo cual se ha identificado entre sí en su Yo (Freud, 1976b: 101 y 108).

No es el caso discutir aquí las ideas de $\mathrm{S}$. Freud sobre las masas, pero esas citas son de sumo valor para este trabajo si se acepta el reemplazo del concepto de caudillo (el elemento más destacado y visible de las masas a través de la historia) por el más impersonal pero categórico y actual de medios masivos de difusión, "caudillos" en definitiva de masas que los siguen, personificados en múltiples oportunidades por héroes carismáticos (actores, líderes de opinión, etc.). Existe el peligro de ver en ese paralelismo una transpolación mecánica de conceptos, pero una evaluación rigurosa puede mostrar que no es así. ${ }^{8}$

Uno de los aspectos por investigar es hasta qué punto las imágenes parentales no resultan de alguna manera devaluadas -y en caso afirmativo, en qué medida y con qué alcances- en relación con los modelos presentados por los medios, modelos lejanos y que no ofrecen la protección y afectos concretos que los niños necesitan, y que sí brindan las figuras con presencia real.

En esta línea J. Mousseau considera que los escandinavos son quienes más han estudiado la identificación de los jóvenes con los héroes televisivos, concluyendo que "juegan un menor papel que la identificación con los padres", aunque agrega que "es únicamente en las familias donde los niños tienen relaciones perturbadas con sus padres y personas cercanas, que éstos buscan modelos en los

8. Tal vez exagerando un poco pero ofreciendo un concepto valioso, Furio Colombo considera que en los países de alta comunicación masiva se está produciendo el fenómeno de desaparición del líder tradicional, lo que para él parece como evidente y demostrable (Colombo, 1976: 34). 
medios" (Mousseau, 1983: 207), postura ésta última poco clara, confusa, ya que no se entiende si quiere decir que en estos casos hay un mayor grado de identificación con los personajes de los medios (lo que resulta muy probable), o si, dada la utilización del término "únicamente", solo se presenta en ellos, lo que no parece válido dado que tales procesos se producen, en niveles variables, en prácticamente todos los niños.

En una línea más amplia se encuentra quien, como Manseur, plantea que "los chicos que son abandonados por sus familias frente al aparato de televisión están forzados a tomar lo que aparece en la pantalla de TV como experiencia primordial" (Peyrú, 1993: 53). Más amplia porque aquí no se reduce el problema a perturbaciones y/o abandonos familiares sino a una realidad muy amplia; en efecto, como ya se planteó anteriormente, es demasiado común que los niños sean colocados durante mucho tiempo frente a la pantalla por diversas causas ya mencionadas, justificadas incluso por los padres. $\mathrm{Al}$ respecto no puede dejarse de lado la observación de G. Peyrú de que "a los quince meses, por su propia maduración y por el entrenamiento adquirido frente a la pantalla, ya pueden imitar la conducta de los modelos televisivos" (Peyrú, 1993: 40).

No es necesario reiterar que los medios, al menos en su utilización dominante actual, siempre promueven la identificación con modelos "positivos", es decir, los que difunden los valores aceptados de un marco social. De esta manera las figuras con arraigo y autoridad fomentan lo que, aunque de una manera exagerada, se indica en un libro muy difundido referente a los dibujos animados:

Como la revista es la proyección del padre, su figura se hace innecesaria y hasta contraproducente [...] La literatura infantil misma sustituye y representa al padre sin tomar su apariencia física. El modelo de la autoridad paterna es inminente a la estructura y existencia misma de esa literatura, subyace implícitamente en todo momento (Dorfman y Mattelart, p. 21).

Pero es un modelo con características importantes de acuerdo con el principio de realidad ya estructurado o en formación: exitosos y triunfadores, generalmente con gran fuerza y poder u omnipotentes (desde Batman o la Mujer Maravilla hasta los héroes de las series televisivas o de las caricaturas), siempre poseedores de belleza física y de todo aquello que se hace ver como importante y deseable (automóviles modernos, ropa de moda, aventuras de todo tipo, etc.), pero también con las características y estereotipos que cada cultura atribuye a las personas y objetos.

En este sentido es que, por ejemplo, G. Peyrú señala:

[...] siguiendo una tradición romántica, casi todos los personajes femeninos, centrales o secundarios, son: dependientes, sensibles, delicados, agradables, tiernos, cálidos, delicados, ligeramente sometidos, alegres, pacíficos. Los hombres por su parte, son en general: activos, inteligentes, prácticos, creativos, fuertes, valientes, independientes, enérgicos, resueltos, violentos, reflexivos, responsables. Es interesante saber que, en estas clasificaciones sexistas y complementarias, cada uno de estos 
rasgos es evaluado como positivo, dentro de su respectivo género, siempre y cuando, claro está, se mantengan separados y correctamente ordenados a ambos lados de la barrera que los separa. Millones y millones de muchachas y muchachos miran diariamente esta pantalla, buscando una guía sobre cómo comportarse de acuerdo con su sexo [...] (Peyrú, 1993: 113-114).

Frente a ellos, vistos como ideales del yo, las figuras reales pueden sufrir en la comparación, pese al vínculo emocional concreto pero siempre con sus contradicciones, por tratarse de personas generalmente alejadas de aventuras y éxitos de los personajes de ficción o de los héroes reales. Así lo comprende un investigador de telenovelas:

El lector en familia está constantemente comparando la telenovela que ve, con la pobre, rica, densa, fútil - según la ubicación de la familia en el espacio socialexperiencia semántica o conductual de fruición de otros textos culturales que ha conocido de manera directa o indirecta, de primera, segunda o enésima mano y ese ejercicio de comparación se reticula en los meandros del poder intrafamiliar (González, 1993: 23).

De manera más concreta y categórica puede decirse:

[...] para muchos adolescentes (y por supuesto también niños) los personajes de televisión son más hermosos, más atractivos, sofisticados y valientes que sus padres, maestros y otras "personas comunes" que los rodean. Comparativamente los adultos cotidianos les parecen "antihéroes" (González, 1993: 90).

Pero independientemente de esto - sobre lo cual por ahora pueden formularse diversas hipótesis, intuiciones y hasta planteos teóricos, pero no conclusiones empíricas definitivas-, lo incuestionable es que, junto a los anteriores aspectos ya vistos, los medios aportan de una manera destacable y cada vez mayor, con lo que ello implica para el papel familiar tradicional respecto de la reproducción y el proceso de constitución del sujeto.

\section{Familia, medios y principios de realidad}

Algo similar ocurre, pero con una mayor aunque polémica comprobación empírica, respecto de la función de los medios en la construcción del principio de realidad, que reemplaza al de placer en la constitución de la instancia yoica.

El principio de realidad es central en la constitución del sujeto psíquico de la teoría psicoanalítica. S. Freud escribe que frente a la imposibilidad del cumplimiento absoluto de los deseos del principio del placer

[i..] se introdujo un nuevo principio en la actividad psíquica: ya no se representó lo que era agradable, sino lo que era real, aunque fuese desagradable; este estableci- 
miento del principio de realidad resultó un paso grávido de consecuencias [...] Al aumentar la importancia de la realidad exterior, cobró relieve también la de los órganos sensoriales dirigidos a este mundo exterior y de la conciencia aplicada a ellos, que, además de las cualidades de placer y displacer (las únicas que le interesaban hasta entonces), aprendió a capturar las cualidades sensoriales. Se instituyó una función particular, la atención, que iría a explorar periódicamente el mundo exterior a fin que sus datos ya fueran consabidos antes de que se instalase una función interior inaplazable [...] Así como el Yo-placer no puede más que desear, trabajar por la ganancia de placer y evitar el displacer, de igual modo el Yo-realidad no tiene más que aspirar a beneficios y asegurarse contra prejuicios (Freud,1976c: 224, 225,228 ).

Independientemente de lo que S. Freud entiende por "realidad" y una posible discusión al respecto, es incuestionable que en la actualidad son los medios los que la presentan de manera dominante en una escala muy superior al de otras instituciones como la familiar, la escolar, la religiosa, etc., y en todos sus mensajes, no sólo en los considerados informativos; si en éstos su presencia es explícita, en otros como historietas, telenovelas, programas culturales e informativos, también pueden serlo de manera implícita, pero inevitablemente al mostrar un determinado contexto social e histórico, caminos de éxito y de fracaso, premios y castigos, etc. (con todo lo que estos también implican el Superyó).

Un analista francés señala:

[...] los medios de comunicación de masas, y especialmente el más difundido en nuestros días, la televisión, tienen por función reexpresa, reinterpretar (o mantener) los símbolos comunes, suscitar otros nuevos, diseminándolos y tornándolos asimilables para masas de individuos cuyos rasgos intelectuales y afectivos son muy variados. La televisión es, en nuestra sociedad tecnificada, el instrumento más poderoso para hacer participar a la masa en sistemas de símbolos cuya difusión común es necesaria para la cohesión social (Friedman, 1969: 84).

Esto tanto por la capacidad de llegada de los medios como porque si bien siempre ha ocurrido, más lo es ahora ante la multiplicidad y rapidez de acontecimiento en el mundo que pueden considerarse "noticias" la capacidad de los sujetos para conocerlas de manera directa se reduce a su siempre muy limitado mundo perceptivo.

Es por esto que investigadores de diferentes marcos teóricos destacan la importancia de los medios. Entre aquellos hay quienes cotundentemente consideran que "los medios informativos son el lugar donde las sociedades industriales producen nuestra realidad" (Verón, 1981: 7), por lo que no resulta nada exagerada la afirmación de Ch. Doelker:

[...] la construcción de nuestra imagen del mundo se realiza cada vez más a través de los medios, que a su vez proporcionan una imagen del mundo. Por consiguiente, nuestro concepto de la realidad nace — según nuestra proporción de consumo de los 
medios-asimismo de experiencias mediatas y no tan sólo de experiencias inmediatas (Doelker, 1982: 177).

Es decir que prácticamente todo nos llega a través de los medios, siempre intermediarios del conocimiento de la realidad, con todo lo que esto implica. ${ }^{9}$ Incluso cuando no pocas veces los testigos de algo necesitan confirmarlo con una voz autorizada que destaque lo visto o su importancia, o se considere verídica una noticia porque "lo dijo la tele" o alguno de sus voceros considerados prestigiados.

En este sentido múltiples investigaciones muestran cómo la TV es el medio informativo más importante en el mundo entero, y más en países como México, donde el nivel de lectura de periódicos, revistas y libros es bajo. En nuestra sociedad "televisualizada" (Erausquin y otros, 1984: 13) la TV se convierte en lo que un comunicólogo define como "maestra de la vida" (Sánchez R. 1989: 9) por ser "una de las actividades aculturizadoras que intervienen en la socialización de la gente" (Martín S., 1986: 38), razón por la cual en general se comparte que en el análisis de su importancia (como parte fundamental de los medios de difusión) debe "considerarse como preocupaciones centrales de la sociología y de la teoría social" (Thompson, 1991: 43) (y también psicológica y psicoanalítica). Pero más allá de la teoría, investigaciones empíricas realizadas en México mostraron que un importante porcentaje considera que lo que se ve en la TV representa la realidad, y cree que viendo las telenovelas se pueden tomar modelos para actuar y aprender a resolver problemas propios (Sánchez R., 1987: 117, 120).

En cuanto a las causas de la constantemente denunciada mayor o menor distorsión de la información -o, en programas de diversiones y similares, presentación de una agradable, bonita y no cuestionante realidad-, ya se sabe que la conducta y la ideología de los hombres siempre estarán basadas en su idea de realidad. De allí la necesidad de ofrecer una que sea coherente con el mantenimiento del sistema de dominación vigente, o enmascarar, distorsionar o silenciar el conocimiento de aquello que no se quiere que se conozca. De esta manera, ante la inexistencia de otras ideas sobre la realidad, el Yo no podrá actuar -y mucho menos de forma eficiente - para modificar una situación que el poder pretende que cambie sólo de acuerdo con sus necesidades. En síntesis, se trata de construir un principio de realidad que garantice dos objetivos centrales: la aceptación mayoritaria de la realidad presente como la normal, la válida y la mejor entre las posibles, así como el rechazo de otras que se presentan como inconvenientes, totalitarias, etc.; y como consecuencia, dificultar o imposibilitar

9. Cada vez más la televisión busca convertirse en el centro de todo lo que ocurre, reemplazando las vivencias directas y la participación de los sujetos incluso en los acontecimientos donde podría hacerlo. Esto ya se ha convertido en cotidiano en los campos políticos (actos de campañas electorales, por ejemplo) y de espectáculos deportivos (los futbolísticos en primer lugar), pero alcanzó su nivel máximo durante el eclipse de sol de hace pocos años cuando apoyándose en la supuesta peligrosidad del fenómeno y en la credulidad de mucha gente, empujó a verlo en las pantallas (lo que no hizo la en ese entonces televisión estatal mexicana). 
las críticas y cambios de lo establecido por el desconocimiento de lo real existente y sus causas, planteos alternativos, etc., incluso en situaciones donde no haya acuerdo con lo existente.

Puede verse que este proceso de presentación de una determinada realidad -que se hace de hecho en todos los marcos sociales, aunque en mayor grado en aquellos donde no existe real pluralidad de medios de difusión- se lleva a cabo desde la más temprana infancia (cuando sus efectos son más duraderos y estructurales), con un permanente reforzamiento posterior.

Todo esto explica el porqué de la búsqueda del control de los medios, instancias hoy hegemónicas en la construcción de la idea de realidad de una sociedad, con todo lo que esto significa. Aspecto fundamental que destacan M. y A. Mattelart con base en la obra de M. Foucault:

El modelo de organización panóptico, utopía de una sociedad, ha servido desde esa perspectiva para caracterizar el modo control, gestionador/organizativo ejercido por la televisión o mejor por el dispositivo televisivo: un modo de organizar el espacio, de controlar el tiempo, de vigilar continuamente al individuo y de asegurar la producción positiva de comportamientos, dejando de lado las formas negativas de represión (Mattelart y Mattelart, 1989: 79).

\section{Lo mismo que con otras palabras señala $\mathrm{G}$. Goethals:}

En una sociedad sumamente compleja, la televisión ha empezado a desempeñar una de las funciones más antiguas y tradicionales de las imágenes: visualizar los mitos comunes e integrar al individuo en el todo social (Goethals, 1986: 14).

No es éste el lugar para reiterar las múltiples formas de hacer creer una determinada "realidad" que no lo es o no lo es tanto, tampoco las trampas para lograrlo, como muchas veces "los acontecimientos que nos presentan los noticieros televisivos a menudo son seudoacontecimientos" (Guattari, 1992: 18), ni que también muchas veces la aparente saturación informativa esconde una real desinformación. Baste destacar aquí lo anterior y su sentido, así como su crucial importancia en lo relativo a la construcción de la subjetividad y de sus modelos de Yo y Superyó, donde "la noticia, como el conocimiento, impone un marco para definir y construir la realidad social" (Tuchman, 1983: 194). Modelo que rechaza lo que no entra dentro del mismo:

Esta instantaneidad del acontecimiento televisivo y de los media hace que la realidad pase a ser lo que sucede en los medios, que generan una inscripción significa en la realidad, un anagrama sintétiço, un tatuaje instantáneo que se superpone sobre lo real y en cierto sentido lo eclipsa o lo sustituye. Hay un plano de realidad que es el que sucede en los media y lo otro pasa a ser una subrealidad, una realidad secundaria y episódica (Patiño, 1993: 59). 
Entonces puede verse que el papel de la familia en la construcción de la realidad, si bien - como en lo anteriormente visto sobre identificaciones- no ha desaparecido, sí se ha reducido mucho, cuantitativamente y cualitativamente, ante el avasallador peso de los medios masivos. Y también aquí se establece una fuerte vinculación familia-medios, donde la primera aparece de múltiples maneras como intermediaria o mediadora en la transmisión de los contenidos de los segundos. En este sentido es muy importante tener en cuenta que los medios llegan a los niños de dos maneras: directa, tal como se mostrará a lo largo de este trabajo, pero también indirecta a través de la familia y sus integrantes, que actúan como transmisores de formas de vida y normas sociales que introyectaron e introyectan de los medios.

Esta presencia de la familia se reitera en múltiples mensajes de los medios, llegando incluso a convertirse en el centro de incontables programaciones. Como lo observa G. Goethals, "sólo se necesita echar una ojeada a los programas de televisión para ver cuán a menudo se emplea a la familia para reflejar un 'mundo' dentro del cual se plantean problemas del comportamiento humano." Y considera:

[...] la familia ha sido una gran imagen metafórica durante toda la historia [...] que aporta un fondo simbólico que puede moldearse para dar acomodo a una gran diversidad de personajes y de principios morales, y al mismo tiempo es uno de los mundos más fáciles de entender con que pueden identificarse los espectadores. En contraste con la naturaleza o la tecnología, la metáfora de la familia pinta nuestros compromisos interpersonales más íntimos, más intensos. Mediante las relaciones de familia conocemos el amor, la confianza, el respeto, la fidelidad, la educación, la lucha por la independencia, y el rutinario toma y daca de la vida cotidiana [...] Cada programa de televisión sobre la familia - sea vulgar o profundo- ofrece a los espectadores interesados una oportunidad de analizar los modos en que las normas sociales están implícita o explícitamente presentes (Goethals, 1986: 59-61).

Sin embargo, esta reiterativa presencia no cambia lo aquí señalado respecto de la disminución, del peso familiar en la presentación del sentido de la realidad.

\section{Superyó, familia y medios}

Luego de todo lo mencionado anteriormente, puede resultar tal vez innecesario mostrar la importancia de los medios en la transmisión de los valores de cada marco cultural concreto. Sin embargo, no puede soslayarse hacerlo ya que, como es sabido, el psicoanálisis plantea la participación sustancial del marco familiar en la formación de la instancia del Superyó, con centro en el complejo de Edipo:

Así, como resultado más universal en la fase sexual gobernada por el complejo de Edipo, se puede suponer una sedimentación del Yo, que se constituye en el establecimiento de estas dos identificaciones, unificadas de alguna manera entre sí. Esta 
alteración del Yo recibe su posición especial: se enfrenta al otro contenido del Yo como ideal del yo o Superyó [...] El ideal del Yo es, por lo tanto, la herencia del complejo de Edipo y, así, expresión de las más potentes mociones y los más importantes destinos libidinales del Ello [...] Lo que en la vida anímica individual ha pertenecido a lo más profundo, deviene, por la formación del ideal, lo más elevado del alma humana en el sentido de nuestra escala de valoración (Freud, 1976a: 35, $37,38)$.

Sin embargo, otros seguidores de la teoría analítica han planteado modificaciones, siendo las más importantes para esta problemática las que indican su aparición cronológica anterior a los que señala S. Freud, así como reforzando la participación de otros factores - autoridades, maestros, etc.- en su génesis, aspecto que ya incluía S. Freud para etapas posteriores.

En el posterior circuito del desarrollo, maestros y autoridades fueron retomando el papel del padre; sus mandatos y prohibiciones han permanecido vigentes en el ideal del Yo y ahora ejercen, como conciencia moral, la censura moral (Freud, 1976a: 38).

$\mathrm{Al}$ igual que lo formulado respecto de los procesos de identificaciones y de construcción del principio de realidad, por supuesto tampoco respecto del Superyó puede negarse el aporte sustantivo de la familia en nuestro presente, pero igualmente sería equivocado negar la incidencia de otras instituciones, la de los medios en particular, por el peso señalado en las páginas anteriores.

Es incuestionable, y poco puede agregarse a todo lo ya estudiado e investigado al respecto, que en prácticamente todos los contenidos de los medios aparece una constante escala de valores de lo que los receptores deben o no deben hacer. Una persona triunfante y aceptada será aquella que cumpla con lo que la moral indica, hace lo que se plantea que es "bueno" y no lo que se muestra como "malo". Los personajes de los medios que deben ser imitados son modelos por sus perfecciones o porque reconocieron los errores cometidos.

En nuestra sociedad se nos enseña que hay ciertas cosas que podemos hacer y otras que no podemos hacer; de este modo se nos introduce a los valores y a las normas. El proceso de socialización, que es continuo y se ubica en las personas y las instituciones, y puede no sólo ser deliberado sino además inadvertido, consiste en parte en la internalización de múltiples "haz esto" y "no hagas aquello", de "bien" y de "mal", de "verdadero" y "falso", propios de la sociedad de que se trate. Ni el contenido ni los métodos de socialización son inmunes a la influencia de los medios de comunicación de masas [...] Los medios de masas, se puede admitir constituyen sólo un proceso, pero sería muy sorprendente, en verdad, si no desempeñaran un cierto papel en la modelación de nuestras actitudes respecto de la vida, de nosotros mismos y de los demás (Halloran, 1969: 29). 


\section{Familia, medios, "salud mental" y psicopatología}

También sobre este aspecto la mayor parte de las teorías psicológicas y psicoanalíticas clásicas señalan el marco familiar como el productor de las psicopatologías de sus integrantes. Aunque algunas de ellas ponen énfasis o reconocen la intervención de otros aspectos - orgánicos o sociales-, la familia mantiene al respecto una importancia crucial y en algunos casos absoluta.

No es el objetivo ni la intención de este apartado discutir una importancia innegable e incuestionable. Sólo interesa hacer mención de algunos aspectos donde los medios intervienen al respecto, sea junto con la familias o aportando ingredientes pertinentes para las por algunos llamadas "patologías del fin del milenio", reconociendo bajo este nombre la incidencia de las actuales formas culturales en la producción del problema (Guinsberg, 1994).

El estudio de esto hace necesarias algunas precisiones, la fundamental de las cuales es recordar que no hay una sola sino múltiples conceptualizaciones de la polivalente noción de "salud mental", término tan usado como rechazado en diferentes teorías psicológicas. Pero en algunos casos se la equipara con "normalidad", planteo que convierte en "sano" lo que no es más que una postura o conducta mayoritaria y aceptada (Guinsberg, 1990).

De esta manera los medios se convierten también en una de las instituciones fundamentales que participan en el señalamiento de lo que se considera "sano" (bueno) o "enfermo" (malo) psicológica y socialmente, todo cargado con las significaciones culturales de una época y una sociedad determinadas. Tal es lo que puede observarse en los personajes y contenidos de la absoluta mayoría de los medios masivos, casi siempre planteados de una manera categórica, simplista y maniquea. De esta manera fomentan, intensifican y refuerzan comportamientos, actitudes y valores acordes con el señalado criterio estadístico de "salud mental", es decir promueven formas de adaptación acríticas y cuestionan las perspectivas críticas bajo el estigma de mostrar como "raros, "enfermos" o "locos" a quienes no coinciden con lo "normal". En esta perspectiva los medios promueven características psíquicas del modelo de hombre "sano" de una época.

Respecto del fomento o producción de "locura" valen las mismas críticas sobre la definición de ésta que para la de "salud mental". Y si bien el presente planteamiento parte de una visión crítica sobre el papel de los medios actuales -que no es su esencia sino la de sus usos presentes-, esta visión crítica no debe confundirse con los simplismos, casi apocalípticos como diría U. Eco (1977), en que caen muchos análisis rudimentarios donde responsabilizan a los medios de prácticamente todo lo que ocurre en la sociedad contemporánea.

Este problema puede considerarse, en principio, desde tres perspectivas distintas aunque no incompatibles y sí articulables entre ellas, con impactos no buscados intencionalmente sino que surgen como consecuencias de las contradicciones inherentes a las características de los distintos sistemas sociales, resultando a veces perturbadores o molestos incluso para el propio marco que los produce. 
Un primer concepto teórico por utilizar —que surge de la filosofía y de la sociología - es el de alienación o enajenación, con antecedentes en Hegel, Feuerbach, Marx, Hess, etc., que hace referencia a la pérdida de algo propio del hombre y depositado en otras instancias convertidas en poseedoras de lo sustraído a aquél.

Si bien, y extrañamente, este concepto está muy poco trabajado en las diferentes teorías psicológicas, su valor es grande para no pocos estudiosos, en cuanto a la influencia de los medios, no es casual que una de las principales acusaciones que se les hace es ser precisamente "alienantes" (aunque las más de las veces en el ya mencionado sentido "apocalíptico"), tanto por la entrega de amplísimos sectores de receptores, como por la identificación con el medio en sí y con sus protagonistas, en diferentes programaciones o productos promocionados. Puede también vincularse alienación con identificación: una ligazón donde la introyección de contenidos (de figuras admiradas, papeles-modelos, mercancías, etc.) significa colocar la propia identidad (o aspectos de ésta en tales figuras y objetos teniéndolos dentro de uno mismo, es decir la presencia de "otros" internalizada.

Este fenómeno alienatorio alcanza sus máximas dimensiones mediante el permanente mensaje publicitario (Guinsberg, 1987) - se vale por lo que se tiene o usa- y la marcada difusión que los medios hacen de otro fenómeno, el deporte, que si bien de por sí no tiene por qué serlo, hoy actúa en tal sentido de manera muy amplia.

El segundo marco teórico para abordar el problema es el psicoanalítico se vincula al principio de realidad y su importancia en la diferenciación entre estructuras neuróticas y psicóticas. Es conocido que el psicoanálisis plantea que la formación yoica se produce al pasar el sujeto del principio del placer a la realidad, así como que la diferencia central entre las estructuras citadas tiene que ver con la forma como la persona se relaciona con la realidad.

$\mathrm{Si}$, como ya se vio, hoy se reconoce que los medios son la fuente principal de presentación de la realidad, iqué ocurre cuando ofrecen una realidad parcial o totalmente falsa o distorsionada. Tal como ha sido y es constantemente denunciado. Y cuando la forma de presentarla es no global sino fragmentaria?

Similares distorsiones surgen como consecuencia de la forma de presentación de la realidad. Por razones técnicas no evitables (transmisión por TV de un partido de futbol, por ejemplo) o por motivos intencionales (con conciencia o no de ello), se ofrece una parte del acontecimiento o de la explicación del hecho, de manera tal que el receptor no percibe la totalidad, con la distorsión que esto ímplica. En muchos casos se pierde así la imprescindible noción de globalidad al percibir partes aisladas y separadas, lo que muchas veces se busca intencionalmente para que no se capte o no haya toma de conciencia de vínculos o causasefectos, impidiéndose o dificultando de esta manera la producción de cambios en lo que se busca que quede como está. Cabe preguntarse en qué medida esta tendencia a la fragmentación dominante en los medios contemporáneos es parte sustancial en la promoción de las tendencias esquizoides existentes y que, por lo 
visto, resultan convenientes y útiles —en tanto controladas- para el mantenimiento de las formas de dominación.

Por lo señalado resulta incuestionable la participación de los medios en el proceso "salud/enfermedad" mental. Al respecto se produce una situación paradójica y confusa: si deben conceptuarse como psicóticas o neuróticas a las personas que en distintos grados pierden el sentido de realidad, iello es válido para niveles masivos al considerar que lo que creen como tal, porque así se lo dicen, en realidad no lo es, o lo es parcialmente? La respuesta a esta problemática no sólo es muy difícil sino indica una vez más la necesidad de estudiar y debatir tanto sobre estas cuestiones como acerca de las nociones de "salud", "normalidad", "enfermedad", etcétera.

Un tercer y último aporte teórico sobre el tema parte de la Teoría del Doble Vínculo de la Escuela de Palo Alto, California, que en líneas harto generales plantea un proceso que consiste en: 1) existen dos o más personas, una de las cuales es la "víctima"; 2) se trata de una experiencia repetida y constante, o sea que es una situación habitual y no ocasional; 3 ) en la misma se produce un doble mensaje: por un lado una instrucción primaria y por otro una secundaria que contradice a la primera en un nivel más abstracto, reforzada ésta por amenazas o castigos (muchas veces comunicada por medios no verbales); 4) una instrucción terciaria que prohíbe o no permite escapar del campo del proceso (Bateson y otros, 1971).

Es cierto que los autores hacen referencia de manera exclusiva al campo microsocial de la familia como campo de producción de la esquizofrenia, pero - sin transpolaciones mecánicas- es importante comenzar a pensar en un "doble vínculo" a niveles macrosociales que llevaría a la creación de un estado esquizoide a niveles masivos.

De las cuatro partes del proceso, tres son bastante obvias en lo referente a los medios: es una experiencia a niveles masivos que se mantiene a través de toda la vida y a la que resulta difícil o imposible escapar (al contrario, en general resulta placentera). En cuanto al punto central, es notoria la sistemática contradicción entre múltiples mensajes manifiestos y latentes que los medios ofrecen de una manera generalizada. Si bien los ejemplos son constantes y en todos los terrenos, tres pueden servir como paradigmas: 1) frente a las constantemente llamadas formas democráticas la estructura de la mayor parte de los medios es vertical y autoritaria, no permiten ni posibilitan el diálogo y la comunicación real con los receptores (cuando de alguna manera esto último existe, muchas veces es limitado o una apariencia: por ejemplo la publicación de cartas de lectores o llamadas por teléfonos abiertos, pero seleccionadas en ambos casos); 2) frente al también constante llamado manifiesto a la solución de los problemas por vías pacíficas y legales se contrapone el uso de una permanente violencia, generalizada en programas y series de gran éxito, en los cuales los superhéroes (de ficción o reales como los de la guerra del Pérsico) implícitamente señalan cuál es el camino del triunfo, sin objeciones respecto de que ello significa la violación de normas morales y legales; 3 ) en lo referente a la sexualidad ocurre algo parecido, se presenta permanentemente una especie de doble código: por un lado (sobre 
todo, pero no exclusivamente, en anuncios publicitarios y en algunas películas) se rompe con la moral y los tabúes tradicionales mediante el placer y el éxito que se obtienen con el erotismo; mientras por otro lado, con frecuencia en los mismos programas se resalta que quienes actúan de tal manera terminan condenadas legal y prácticamente.

Más allá de estas tres perspectivas, algunos investigadores han planteado otros aspectos. Por ejemplo, una psicoanalista que podría definirse como del campo tradicional e institucional de ese marco teórico no sólo destaca la ya señalada disminución de los vínculos de comunicación familiares, sino incluso formula la televisiosis o televisitis como "una enfermedad mental bastante seria que encuadramos como 'situación crítica', o sea, posible de sucumbir a la desorganización psicótica y transformarse en sicosis", algunas de cuyas características psicopatológicas son: persistencia de la utilización masiva de la identificación proyectiva, tal como ocurre en los primeros meses de vida; tendencia hacia la regresión de los estados iniciales del desarrollo mental; intensas ansiedades persecutorias; manía, omnipotencia, control omnipotente, conversión de lo siniestro en maravilloso, tendencia a la imitación y al sometimiento; persistencia de la simbiosis y del narcisismo infantil; ansiedades fóbicas; dispersión de la atención y dificultad para concentrarla; etc. (Soifer, 1981: 55 y ss.).

Por supuesto que lo señalado es sólo un inicio que requiere de mucha mayor elaboración y profundización, lo mismo que la incorporación de planteamientos no mencionados aquí. Indicación que se hace extensiva para todas las proupuestas de este trabajo.

\section{Bibliografía}

Arredondo Ramírez, Pablo (1989). "Presentación”, en Enrique Sánchez Ruiz, (comp), Teleadicción infantil: imito o realidad?, Universidad de Guadalajara.

Bateson, Gregory, Don Jackson, Jay Haley y John Weakland (1971). "Hacia una teoría de la esquizofrenia", en el libro de varios autores, Interacción familiar. Aportes fundamentales sobre teoría y técnica, Tiempo Contemporáneo, Buenos Aires.

Colombo, Furio (1976). Televisión: la realidad como espectáculo, $2^{\mathrm{a}}$ ed., Gustavo Gili; Barcelona.

Cooper, David (1971). La muerte de la familia, Paidós, Buenos Aires.

Corona, Sarah (1989). Televisión y juego infantil. Un encuentro cercano, Universidad Autónoma Metropolitana-Xochimilco, México.

Doelker, Christian (1982). La realidad manipulada, $5^{\mathrm{a}}$ ed., Gustavo Gili, Barcelona.

Eco, Umberto (1977). Apocalípticos e integrados, Lumen, Barcelona.

Erausquin, A., L. Matilla y M. Vásquez (1984). Los teleniños, Fontamara, México. 
Freud, Sigmund (1976a). "El Yo y el Ello", en Obras completas, t. XIX., Amorrortu, Buenos Aires.

- (1976b). "Psicología de las masas y análisis del Yo", en Obras completas, t. XVIII, Amorrortu, Buenos Aires.

- (1976c). "Formulaciones sobre los dos principios de acaecer psíquico", t. XII. Amorrortu, Buenos Aires.

Friedman, Georges (1969). "La televisión vivida", en Los efectos de las comunicaciones de masa, Jorge Álvarez editor, Buenos Aires.

Gil Olivo, Ramón (1987). “Televisión y cultura en dos comunidades purépechas", en María Rebeil Corrella y Alberto Montoya Martín del Campo, Televisión y desnacionalización, Universidad de Colima/Asociación Mexicana de Investigadores de la Comunicación, Colima.

Goethals, Gregor (1986). El ritual de la televisión, Fondo de Cultura Económica, México.

González, Jorge A. (1993). "El regreso de la cofradía de las emociones interminables. Telenovela y memoria en familia", Telos, número 4, Madrid.

Guattari, Félix (1992). "La era post-mediática”, entrevista de Florence Olivier en La Jornada Semanal, número 176, México, 25 de octubre.

Guinsberg, Enrique (1985). Control de los medios, control del hombre. Medios masivos y formación psicosocial, Nuevomar, México, 2ª ed., Pangea/UAM-X, 1988.

(1987). Publicidad: manipulación para la reproducción, Plaza y Valdés, México.

(1990). Normalidad, conflicto psíquico, control social, $2^{\text {a }}$ ed., Plaza y Valdés, México.

(1991a). "Recuperar el estudio del receptor. Dialéctica subjetivo-social en los medios masivos", Telos, Fundesco, núm. 25, Madrid.

(1991b). “ ¿En la búsqueda de nuevos paradigmas para el estudio de la comunicación?”, Comunicación y Sociedad, número 10-11, Universidad de Guadalajara.

(1991c). "La relación hombre-cultura: eje del psicoanálisis", Subjetividad y Cultura, número 1, México.

- (1994). "El psicoanálisis y el malestar en la cultura neoliberal", Subjetividad y Cultura, número 3, México, reproducido en la 2 a ed. de Normalidad, conflicto psíquico, control social.

- (1997). “¿Que buscan lo receptores? Una perspectiva psicológica y psicoanalítica", Telos núm. 48, Fundesco, Madrid.

Halloran, J. D. (1969). "Examen de los efectos de comunicación de masas con especial referencia a la televisión", en varios autores, Los efectos de las comunicaciones de masas, Jorge Álvarez Editor, Buenos Aires.

Laing, Ronald (1976). El cuestionamiento de la familia, Paidós, Buenos Aires. 
Laplanche, Jean y Jean-Bertrand Pontalis (1971). Diccionario de psicoanálisis, Labor, Barcelona.

Maletzke, Gerhard (1976). Sicología de la comunicación social, Época, edición CIESPAL.

Marcuse, Herbert (1971). "La doctrina de los instintos y la libertad", en varios autores, Freud y la actualidad, Barral Editores, Barcelona.

-(1986). Eros y civilización. Una investigación filosófica sobre Freud, Joaquín Mortiz, México.

Martín Serrano, Manuel (1986). La producción social de comunicación, Alianza Universidad Textos, Madrid.

Mattelart, Armand (1977). Multinacionales y sistemas de comunicación, Siglo XXI, México.

Mattelart, M. y A. Mattelart (1989). El carnaval de las imágenes, Akal, Madrid. Moffat, Alfredo (1988). Entrevista a Víctor Muleiro, "Indicadores de la destrucción familiar", revista Crisis, núm. 57, Buenos Aires.

Mousseau, Jacques (1983). "Los niños y la TV", en varios autores, La ventana electrónica, Colección Comunicación de Ediciones Eufesa, México.

Orozco Gómez, Guillermo (1992). "La televisión y los niños de nivel preescolar”, en Revista Mexicana de Comunicación, núm. 21, México.

Patiño, Antón (1993). "El principio de la instantaneidad", en Telos, número 36, Madrid.

Peyrú, G. (1993). Papá, ¿puedo ver tele?, Paidós, Buenos Aires.

Sánchez Ruiz, Enrique (1987). “Televisión, socialización y educación informal en Guadalajara", en Rebeil Corella y Montoya Martín del Campo, Televisión y desnacionalización.

-(1989). "Introducción" al libro Teleadicción infantil: imito o realidad?, Universidad de Guadalajara.

Schneider, Michael (1979). Neurosis y lucha de clases, $2^{\text {a }}$ ed., Siglo XXI, Madrid.

Soifer, Raquel (1981). El niño y la televisión, Kapeluz, Buenos Aires.

Thompson, John B. (1991). "La comunicación masiva y la cultura moderna. Contribución a una teoría crítica de la ideología”, en Versión, número 1, revista de la UAM-Xochimilco, México.

Tuchman, G. (1983). La producción de la noticia. Estudio sobre la construcción de la realidad, Gustavo Gili, México.

Verón, Eliseo (1983). Construir el acontecimiento, Gedisa, Buenos Aires.

Watzlawick, Paul (1981). ¿Es real la realidad?, Herder, Barcelona.

Wright Mills, C. (1957). La élite del poder, Fondo de Cultura Económica, México. 